\title{
POLA PENDEKATAN DAKWAH BERKELANJUTAN: PERSPEKTIF MODAL SOSIAL
}

\author{
Abdul Najib, Zuhaeriyah \\ email. Ainunnajib524@gmail.com
}

\begin{abstract}
Current model of dakwah has to deal with complexity of challenges. In tacking such complexity, relevant and contextual approaches are necessarily needed. One of them is social capital based approach. This approach highlights aspects of trust and honesty, norm and values, networking, solidarity, responsibility, local wisdom, local culture, harmony and quality of life. The use of this approach has already been able to answer the challenge of current Dakwah. From the perspective of social capital, the use of basic values from it contributes to the dai's credibility building. This credibility results in sustainable activities of dakwah and therefore, creates more effective results. The effectiveness of sustainable dakwah emphasizes on efforts to set up good self-image for the da'i and improved relevant relational patterns with the mad'u.
\end{abstract}

Keyword: Dakwah, Sustainability, Social Capital.

\section{A. Pendahuluan}

Dakwah merupakan aktivitas seorang Muslim untuk menyebarkan ajaran Islam ke muka bumi yang penyampaiannya diwajibkan kepada setiap Muslim, yang mukalaf sesuai dengan kadar kemampuannya. ${ }^{1}$ Dalam

1 Sebagaimana yang termaktubdalam alQur'an,Surat Ali-Imran:104 sbb Departemen Agama RI, Al-qur'an dan terjemahnya (Jakarta: 1976), hal. 688. ajaran agama Islam, ia merupakan suatu kewajiban yang dibebankan oleh agama kepada pemeluknya, yang berisi seruan kepada keinsyafan, atau mengubah situasi tertentu kepada yang lebih baik dan sempurna, baik terhadap pribadi maupun masyarakat. ${ }^{2}$ Tujuan dakwah adalah mengubah

2 M. Quraish Shihab, Membumikan AlQur'an (Bandung: Mizan, 1998), hal. 194. 
tingkah laku manusia, dari tingkah laku yang negatif ke tingkah laku yang positif. Sebagai seorang juru dakwah hendaklah dapat memahami kondisi yang menjadi objek dakwahnya. Ia harus mampu melihat persoalanpersoalan dengan lebih teliti dan mampu untuk memberikan solusiyang terbaik dalam setiap permasalahan. Oleh karena itu, persoalan dakwah tidak bisa terlepas dengan persoalan realita yang terjadi dalam masyarakat.

Dalam menanggapi persoalanpersoalan dakwah cukup banyak pendekatan/metode dakwah ${ }^{3}$ yang telah dikemukakan dan dipraktikkan oleh para da'i dalam menyampaikan dakwah, seperti ceramah, diskusi, bimbingan, penyuluhan, dan sebagainya. Semuanya dapat diterapkan sesuai dengan kondisi yang dihadapi. Tetapi harus digaris bawahi bahwa pendekatan yang baik sekalipun tidak menjamin hal yang baik secara otomatis, karena metode bukanlah satu-satunya kunci kesuksesan. Akan tetapi, keberhasilan dakwah ditunjang dengan seperangkat syarat, baik dari pribadi da'i, materi, cara yang digunakan, subjek dakwah, ataupun yang lainya. ${ }^{4}$

3 Metodedakwah adalah cara-cara menyam- paikan pesan kepada objek dakwah, baik itu kepada individu, kelompok maupun masyarakat agar pesan-pesan tersebut mudah diterima, diyakini dan diamalkan. Lihat. Shalahudin Sanusi, Pembahasan Sekitar PrinsipPrinsip Dakwah Islam (Semarang: Ramadhani, 1964), hal. 111.

4 Ibid.,hal. 195.
Oleh karena itu melalui tulisan ini, penulis berusaha untuk menemukan atau paling tidak mengungkapkan konsep dakwah yang berkelanjutan yang berlandaskan nilai berbasis modal sosial, karena semakin berkembangnya pola hidup manusia saat ini telah menyebabkan manusia disibukkan dengan tanggung jawab terhadap dirinya dan melupakan tanggung jawabnya kepada keluarga, kaum, atau kampung halamannya. Sebagaimna pendapat Jalal bahwa konsep dakwah idealnya adalah dakwah yang tidak menyempitkan cakrawala umat dalam pemahaman keagamaan dan kedudukan sosial dalam masyarakat. ${ }^{5}$

Dakwah yang diperlukan adalah yang mendorong pelaksanaan dan peningkatan kehidupan sosial, dikarenakan pada lapisan bawah (masyarakat awam) khususnya kebutuhan, yang semakin mendesak adalah melepaskan diri dari himpitan hidup yang semakin berat sehingga diperlukan proses diversifikasi atau penganekaragaman dalam kegiatan dakwah yang terus menerus. Berangkat dari sebuah kegelisahan pelaksanaan dakwah saat ini, dengan materi yang disampaikan da'i yang condong kearah normatif. Terhadap persoalan-persoalan dakwah yang ada penulis menyadari sebenarnya sudah banyak pemikir dakwah yang mencoba memecahkannya, baik pada tingkat wacana maupun praksis. Selain

5 Jalaluddin Rakhmat, Islam Aktual; Refleksi Sosial Seorang Cendekiawan Muslim (Bandung: Mizan, 1991),hal. 155. 
itu yang menarik bagi penulis untuk mengkaji dakwah berbasis modal sosial adalah ingin mengungkap beberapa persoalan penting dan kontribusi modal sosial dalam menciptakan sustanabilitas akan proses dakwah guna untuk menjunjung tinggi kredibilitas ${ }^{6}$ pendakwah.

\section{B. Model Dakwah Berbasis Modal Sosial}

Konsep dakwah memiliki makna yang kompleks. ${ }^{7}$ Aspek penting

6 Kredibilitas memilki kaitan yang erat dengankarisma.Dengan demikian kredibilitas da'i adalah kualitas, kapabalitas atau kemampuan untuk menimbulkan kepercayaan.

7 Sedangkan ditinjau dari segi terminologi, banyak sekali perbedaan pendapat tentang definisi dakwah di kalangan para ahli, antara lain: (1) Menurut A. Hasmy dalam bukunya Dustur DakwahMenurut al-Qur'an, mendefinisikan dakwah yaitu: mengajak orang lain untuk meyakini dan mengamalkan akidah dan syariat Islam yang terlebih dahulu telah diyakini dan diamalkan oleh pendakwah itu sendiri. Lihat, jugaA.Hasmy, Dustur Dakwah menurut alQur'an (Jakarta: Bulan Bintang,1997), hal. 18. (2) Lihat, juga menurut Syekh Ali Mahfud. Dakwah Islam adalah memotivasi manusia agar melakukan kebaikan menurut petunjuk, menyuruh mereka berbuat kebajikan dan melarang mereka berbuat kemungkaran, agar mereka mendapat kebahagian dunia dan akhirat. Lihat, jugaM Kholili, Pokok-Pokok Pikiran Tentang Psikologi (Yogya, UD. Rama, 1991) hal. 66. (3) Lihat, juga menurut Amrullah Ahmad .ed., dakwah Islam merupakan aktualisasilmani (Teologis) yang dimanifestasikan dalam suatu sistem kegiatan manusia beriman dalam bidang kemasyarakatan yang dilaksanakan secara teratur untuk mempengaruhi cara merasa, berpikir, bersikap, dan bertindak manusia pada tataran kegiatan individual dan sosio kultural dalam rangka mengesahkan terwujudnya ajaran Islam dalam semua segi kehidupan dengan cara tertentu. Lihat. Amrullah Ahmad,ed. Dakwah dan Perubahan sosial (Yogyakarta: Prima Duta, 1983), hal 2. (4) Lihat, juga menurut Amin Rais, dakwah adalah gerakan simultan dalam berbagai yang diuraikan dalam sub ini adalah terkait dengan model dakwah khususnya bagi kalangan da'i untuk mempertimbagkan pendekatan dakwah yang digunkan salah satunya adalah dengan mmenekankan aspek modal sosial (social capital). Menurut Coleman "Social Capital" adalah kemampuan masyarakatuntukbekerja bersama-sama demi mencapai tujuan bersama di dalam berbagai kelompok dan organisasi. Modal sosial adalah bagian dari organisasi sosial seperti kepercayaan, norma dan jaringan yang dapat meningkatkan efisiensi masyarakat dengan memfasilitasi tindakan yang terkoordinasi. Modal sosial didefinisikan sebagai kapabilitas yang muncul dari kepercayaan umum di dalam sebuah masyarakat. Modal

bidang kehidupan untuk mengubah status quo agar nilai-nilai Islam memperoleh kesempatan untuk tumbuh subur demi kebahagiaan seluruh umat manusia. Lihat. Amin Rais,Cakrawala Islam (Bandung,: Mizan 1991), hal 26. (5) Lihat, juga menurut Farid Ma'ruf Noor, dakwah merupakan suatu perjuangan hidup untuk menegakkan dan menjunjung tinggi undangundang Ilahi dalam seluruh aspek kehidupan manusia dan masyarakat sehingga ajaran Islam menjadi shibghah yang mendasari, menjiwai, dan mewarnai seluruh sikap dan tingkah laku dalam hidup dan kehidupannya.Lihat, juga menurut Farid Ma'ruf Noor, Dinamika dan Akhlak Dakwah (Surabaya: Bina Ilmu, 1981), hal.29. (6) Lihat, juga menurut Abu Bakar Atjeh, dakwah adalah seruan kepada semua manusia untuk kembali dan hidup sepanjang ajaran Allah yang benar, yang dilakukan dengan penuh kebijaksanaan dan nasehat yang baik. Lihat. Abu Bakar Atjeh, Beberapa Catatan Mengenai Dakwah Islam (Semarang: Ramadani, 1979), hal. 6. (7) Lihat, juga menurut Toha Yahya Umar, dakwah adalah mengajak manusia dengan cara bijaksana ke jalan yang benar sesuai dengan perintah Tuhan, untuk keselamatan dan kebahagiaan dunia akhera. Lihat, juga.Toha Yahya Oemar, Ilmu Dakwah (Jakarta: Wijaya,1976), hal. 1. 
sosial diartikan sebagai serangkaian nilai (norma) informal yang dimiliki bersama dalam suatu kelompok yang memungkinkan terjalinnya kerjasama. $^{8}$ Menurut Cohen dan Prusak menjelaskan modal sosial sebagai stok dan hubungan yang aktif antar masyarakat. Setiap pola hubungan yang terjadi diikat oleh kepercayaan (trust) saling pengertian (mutual understanding), dan nilai-nilai bersama (shared value) yang mengikat anggota kelompok untuk membuat kemungkinan aksi bersama dapat dilakukan secara efisien dan efektif. Berdasarkan keterangan di atas, maka modal sosial sangat berkaitan dengan kegiatan suatu kelompok atau masyarakat untuk meningkatkan kesejahteraan sosial yang mengandung unsur: Kepercayaan dan kejujuran( trust and honesty), norma dan nilai (norm and values), jaringan kerja (networking), kesetiakawanan sosial (solidarity), tanggungjawab (responsibility), kearifan lokal (local wisdom), keselarasan (harmony). Dari gambaran di atas, yang menjadi titik fokus dalam tulisan ini ingin menggali atau menekankan bahwa juru dakwah dalam melakukan dakwah adalah perlu menekankan asas pendekatan modal sosial sebagai berikut:

1. Kepercayaan dan kejujuran (trust and honesty). Unsur penting dalam modal sosial adalah trust.

8 Francis Fukuyama, Trust : Kebijakan Sosial dan Penciptaan Kemakmuran. diterjemahkan bahasa Indonesia Tahun 2002. (Yogyakarta: Penerbit Qalam, 1995), hal. 12.
Hilangnya minat masyarakat terhadap dakwah konvensional disesbabkan karena hilangnya trust. Beda halnya dulu ketika masa-masa Islam awal. Hal ini tidak dimiliki oleh para da'i masa kini, jika hal ini dibiarkan maka akan tetap normatif dan tidak adanya proses transformasi sosial yang merupakan hakikat dari dakwah itu sendiri.

2. Norma dan nilai (norm and values), bagi kalangan pelaku dakwah dalam mengemban strategi dakwahnya perlu memperhatikan aspek etis dari beberapa noramnorma dan nilai yang diamut oleh masyarakat secara umum. Hal ini dapat memandu para da'i untuk berdakwah secarakontekstual dan situasional serta mampu membangun nilai-nilaiindigenisitas bagi mad'u.

3. Jaringan (networking), aspek penting dari modal sosial adalah membangun jejaring sosial bagi masyarakat. Sebagai contoh, dalam praktik dakwah bil hal aktor dakwah mampu mengarahkan mad'u dalam membangun konektivitasnya seperti model dakwah TGH. Hasanain Djuani, Lc., MH yang selain kemampuan retorika yang mapan serta dapat memberikan contoh melalui program sejuta pohonnya.

4. Kesetiakawanan sosial (solidarity), nilai ini juga perlu di bangun dalam menciptakan suasana sustainablity yaitu selain kita mengajak kepada 
hal amar ma'ruf nahi-mungkar perlu juga menjunjung tinggi nilainilai persaudaraan (basic human right) yang bagian juga dari amar ma'ruf nahi-mungkar.

5. Tanggungjawab (responsibility), nilai tanggung jawab merupakan sikap etis bagikalangan da'i. Tanggungjawabtidakhanyasebatas pada saat proses penyampaian materi dakwah saja, namun perlu juga meninjau apakah masyarakat mengalami proses perubahan pada diri mereka serta mampu berbenah secara sosial maupun ekonomi.

6. Kearifan lokal (local wisdom), isu kearifan lokal ini merupakan salah satu bagian dari modelmanajmen dakwah yang mengggunakan aspek nilai-nilai kemasyarakatan yang sesuai dengan pola mereka/ self determination terminologi ini mampu memberikan sikap mandiri bagi masyarakat.

7. Keselarasan (harmony), prinsip dakwah adalah persamaan tanpa membedakan antara da'i dan mad'u dari aspek mobilitasnya, bila hal ini terjamin maka tidakakan terjadi geep/kesenjangan antara keduanya.

Dasar dari pengetahuan di atas, cukup jelas bahwa dalam mementuk model dakwah yang berkelanjutan; peran akan eksistensi pendekatan modal sosial memiliki keterkaitan yang erat dalam membangun kredibilitas da'i dan mempengaruhi dalam berbagai aspeksosial.

\section{Kontribusidan ImplikasiModal Sosial Terhadap ModelDakwah Berkelanjutan}

Tantangan yang paling berat di lingkungan dakwah adalah karenada'i harus berhadapan dengan mad'u yang multikultural dan rasional khususnya di area perkotaan. Lingkup modal sosial seperti; kepercayaan dan kejujuran, norma dan nilai, jaringan kerja, kesetiakawanan sosial, tanggungjawab, kearifan lokal, tradisi, dan keselarasan. Dapat membentuk dakwah yang berkelanjutan. Sebagai contoh, salah satu model dakwah yang memperhatikan keberlanjutan dan penekananpadaaspekmodalsosialyaitu dakwah akan terwujud pada kehidupan masyarakat manakala dakwah dilakukan secara profesional. ${ }^{9}$ Artinya profesional mampu mengeksplorasi serta mengkontekstualisasikan materi dakwah berbasis kebutuhan dasar masyarakat. Kunci utama dalam keberhasilan dakwah terutama dakwah yang berkaitan dengan dakwahbilhal, bil-kitaabah, bil-hikmah, biliqtishadiyah, dan sebagainya. Sebagaimana diketahui bahwa saat ini, bisa dikatakan sebagian besar umat Islam masih berada di bawah garis kemiskinan dan kesejahteraan. Di lain pihak kemajuan ilmu pengetahuan dan teknologi melaju pesat. Mengamati banyaknya problematika umat dewasa ini, menuntut kehadiran dakwah lebih

9 Cecep Sastrawijaya, Konsep dan Pemikiran Manajemen Dakwah Inu Taimiyah dan Imam al-Gazali dalam Terapi Hat. Dalam JurnalKajian Dakwah dan Komunikasi.Vol XIII, No.1 Juni 2009. Hal. 69. 
luas. Dengan demikian, perlu menata dakwah yang holistik dalam menjawab problematika umat. Dapat dikatakan bahwa kegiatan dakwah yang dilakukan dewasa ini, pada umumnya barulah pada tahap menyeru umat agar berbuat baik, beribadah dan membangun keshalehan pribadi. Tetapi seberapa intensifkah kita sebagai para pendakwah berbicara tentang realitas sosial, tantangan abad informasi, ancaman kultural dan berbagai problema ekonomi yang menghadap umat.

Kemudian, persoalan mendasar yang tidak kalah penting sebagaimana disebutkan adalah masalah ekonomi. Karena sekaranginitidakbisa dielakkan adanya ekonomisasi dunia. Semua serba memakai ukuran ekonomi. Dan tampaknya, kalau umat Islam tidak terlibat, kita akan ketinggalan dan akan menjadi pemain pinggiran. Untukitu sangat dibutuhkan kesadaran kultural umat Islam untuk saling bahumembahu dalam rangka membangun kesejahteraan kaum muslimin. Klaim era ini banyak stigmatisasi terhadap juru dakwah terkait dengan isuisu yang negatif. Cara membangun kembali stigmatisasi tersebut yaitu dengan penguatan modal sosial. Sebagaimana telah dipaparkan di atas bahwa modal sosial yang terpenting adalah trust yang merupakan tumpuan dalam membangun hubungan dan jejaring sosial secara terintegratif.

Adanya trust dan perasaan saling membutuhkan dan saling keterkaitan di bidang sosial kemasyarakatan, sehingga secara kultural lebih mudah diterima oleh masyarakat. Trust merupakan inti dari aktivitas modal sosial sehingga ber impact untuk samasama mementingkan kepentingan bersama di atas kepentingan pribadi. Trust merupakan sumber energi utama yang dapat membuat seseorang untuk bertahan dan berpegang teguh. Sasaran utama dakwah adalah menciptakan tatanan suasana sosial yang religius.

Tuntutan dakwah berbasis modal sosial adalah; dakwah mesti diawali dengan kebutuhan masyarakat, dakwah mesti dilakukan secara terpadu, dakwah dilakukan secara partisipasi, dakwah dilakukan melalui sistematika pemecahan masalah, dakwah mesti dilakukan asas swadaya dan kerjasama masyarakat. ${ }^{10}$ Dengan cara ini dakwah dapat dijadikan sebagai kekuatan moral yang merupakan pokok dalam perspektif modal sosial dalam menuntun sustainabilitasnya.

Dengan meninjau beberapa pemaparan sebelumnya yang menerangkanbeberapakonsepdakwah dan modal sosial serta penjelasannya, maka tidak menutup kemungkinan bahwaperan darinilai-nilaimodal sosial bila ditanamkan dalam diri da'i dalam mempengaruhi mad'unya ${ }^{11}$ akan

10 Hatmansyah. Dakwah dan Pemeberdayaan Masyarakat Miskin. Dalam Jurnal Alhadarah. Volume 5 No. 8 Juli-Desember 2006. Hlm.18-19

11 Makna mad'u di atas sebagai objek dakwah yang merupakan setiap orang atau sekelompok orang yang dituju atau menjadi sasaran suatu kegiatan dakwah. Berdasarkan 
dapat menjunjung tinggi kredibilitas pelaku da'i atau (subjek dakwah dapat diartikan sebagai yang melaksanakan tugas-tugas dakwah, orang itu disebut da'i/muballigh). ${ }^{12}$ Untuk menciptakan dakwah yang berkelanjutan mestinya para da'i menyampaikan materi dakwahnya bersifat informatif dan inovatif hal ini dapat mengarahkan para mad'u untuk memahami konsep dakwahnya. Sebagai contoh, pelaku dakwah mampu menseliti materimateri dakwah berbasis pemberdayaan yang dibangun di atas nilai-nilai lokal serta penguatan jejaring sosial. Karena fungsi dari pemberdayaan asas nilai lokal adalah memberi kekuatan atau penguatan kapasistas diri untuk setiap individu. Perlu dicatat bahwa memberikan landasan pemberdayaan terhadap mad'u merupakan bagian dari dakwah bil-hal yang merupakan hakikat dari amar ma'ruf nahi mungkar. Sustainabilitas akan tercipta bila ditinjau dari perspektif generalis dan tidak membatasi hal-hal yang bersifat normatif. ${ }^{13}$

pengertian tersebut maka setiap manusia tanpa membedakan jenis kelamin, usia, pekerjaan, pendidikan, warna kulit, dan lain sebagainya, adalah sebagai objek dakwah. Hal ini sesuai dengan sifat keuniversalan dari agama Islam dan tugas kerisalahan Rasulullah. Lihat. A.Karim Zaidan, Asas al-Dakwah, diterj. M. Asywadie Syukur dengan judul Dasar-dasar Ilmu Dakwah (Jakarta: Media Dakwah,1979), hal. 69.

12 Masdar Helmy. Dakwah dalam Alam Pembangunan (Semarang: Toha Putra, 1975), hal. 47.

13 Hatmansyah. Dakwah dan Pemeberdayaan Masyarakat Miskin. Dalam Jurnal Alhadarah. Volume 5 No. 8 Juli-Desember 2006. Hlm.18-19
Dengan demikian dalam rangka membebaskan umat dari sifatsifat kejahiliahan modern dengan pendekatan bilhikmah. Menurut Enjang yang mengutib dari pandangan Sayid Quthub bahwa dakwah dengan metode hikmah bil-hal akan terwujud apabila memperhatikan tiga faktor. Pertama, keadaan dan situasi orangorang yang didakwahi. Kedua, ada atau ukuran materi dakwah yang disampaikan agar mereka tidak merasa keberatan dengan beban materi tersebut. Ketiga, metode penyampaian materi dakwah dengan membuat variasi sedemikian rupa yang sesuai dengan kondisi pada saat itu salah satunya adalah penekanan pada aspek modal sosial. ${ }^{14}$

\section{Daftar Pustaka}

Al-qur'an dan terjemahnya Kemenag RI (Jakarta: 1976)

Ahmad, Amrullah ed. (1983). Dakwah dan Perubahan sosial. Yogyakarta: Prima Duta.

As,Enjang.(2009).Dasar-dasar Ilmu Dakwah, Pendekatan Filosofis dan Praktis. Bandung: Widya Padjadjaran.

Atjeh, Abu Bakar. (1979).Beberapa Catatan Mengenai Dakwah Islam. Semarang: Ramadani.

Fukuyama, Francis.Trust : Kebijakan Sosial dan Penciptaan Kemakmuran. diterjemahkan

14 Enjang As, Dasar-dasar Ilmu Dakwah, Pendekatan Filosofis dan Praktis (Bandung: Widya Padjadjaran, 2009). hal. 89. 
bahasa Indonesia Tahun 2002. Yogyakarta: Penerbit Qalam, 1995.

Hasmy`, A. (1997).Dustur Dakwah menurut al-Qur'an. Jakarta: Bulan Bintang.

Hatmansyah. "Dakwah dan Pemeberdayaan Masyarakat Miskin”. Dalam Jurnal Alhadarah. Volume 5 No. 8 JuliDesember 2006.

Helmy, Masdar. (1975).Dakwah dalam Alam Pembangunan. Semarang: Toha Putra.

Kholili, M. (1991) Pokok-Pokok Pikiran Tentang Psikologi. Yogya, UD. Rama.

Noor`, Farid Ma’ruf. (1981). Dinamika dan Akhlak Dakwah. Surabaya: Bina Ilmu,.

Oemar, Toha Yahya. (1976). Ilmu Dakwah. Jakarta: Wijaya.

Rakhmat, Jalaluddin. (1991).Islam Aktual; Refleksi Sosial Seorang Cendekiawan Muslim.Bandung: Mizan.
Rais, Amin. (1991). Cakrawala Islam. Bandung: Mizan.

Shihab, M. Quraish. (1998). Membumikan Al-Qur'an. Bandung: Mizan.

Sanusi, Shalahudin.(1964).Pembahasan Sekitar Prinsip-Prinsip Dakwah Islam. Semarang: Ramadhani.

Sastrawijaya, Cecep. "Konsep dan Pemikiran Manajemen Dakwah Inu Taimiyah dan Imam al-Gazali dalam Terapi Hati”. Dalam Jurnal Kajian Dakwah dan Komunikasi. Vol XIII, No.1 Juni 2009.

Siddiq, Syamsuri .(1983). Dakwah dan Teknik Berkhutbah. Bandung: Al-Ma'arif.

Tasmara, Toto. Komunikasi Dakwah. Jakarta: Gaya Media Pratama, 1974.

Toffler, Alvin. (1973).The Third Wave. Jakarta: Panca Simpati.

Zaidan, A. Karim. (1979).Asas alDakwah, diterj. M. Asywadie Syukur dengan judul Dasar-dasar Ilmu Dakwah. Jakarta: Media Dakwah. 